\title{
Methods for Prediction of Steel Temperature Curve in the Whole Process of a Localized Fire in Large Spaces
}

\author{
Zhang Guowei, ${ }^{1,2}$ Zhu Guoqing, ${ }^{1}$ Yuan Guanglin, ${ }^{2}$ and Huang Lili ${ }^{3}$ \\ ${ }^{1}$ School of Safety Engineering, China University of Mining and Technology, Xuzhou 221116, China \\ 2 Jiangsu Key Laboratory for Environmental Impact and Structural Safety in Civil Engineering, Xuzhou 221116, China \\ ${ }^{3}$ Institute of Industry Technology, Guangzhou and Chinese Academy of Sciences, Guangzhou 510000, China
}

Correspondence should be addressed to Zhu Guoqing; zgw119xz@gmail.com

Received 4 October 2013; Revised 2 December 2013; Accepted 10 December 2013; Published 5 January 2014

Academic Editor: Oluwole Daniel Makinde

Copyright (C) 2014 Zhang Guowei et al. This is an open access article distributed under the Creative Commons Attribution License, which permits unrestricted use, distribution, and reproduction in any medium, provided the original work is properly cited.

\begin{abstract}
Based on a full-scale bookcase fire experiment, a fire development model is proposed for the whole process of localized fires in largespace buildings. We found that for localized fires in large-space buildings full of wooden combustible materials the fire growing phases can be simplified into a $t^{2}$ fire with a $0.0346 \mathrm{~kW} / \mathrm{s}^{2}$ fire growth coefficient. FDS technology is applied to study the smoke temperature curve for a $2 \mathrm{MW}$ to $25 \mathrm{MW}$ fire occurring within a large space with a height of $6 \mathrm{~m}$ to $12 \mathrm{~m}$ and a building area of $1500 \mathrm{~m}^{2}$ to $10000 \mathrm{~m}^{2}$ based on the proposed fire development model. Through the analysis of smoke temperature in various fire scenarios, a new approach is proposed to predict the smoke temperature curve. Meanwhile, a modified model of steel temperature development in localized fire is built. In the modified model, the localized fire source is treated as a point fire source to evaluate the flame net heat flux to steel. The steel temperature curve in the whole process of a localized fire could be accurately predicted by the above findings. These conclusions obtained in this paper could provide valuable reference to fire simulation, hazard assessment, and fire protection design.
\end{abstract}

\section{Introduction}

With the increasing public demand for building space and architectural aesthetics, more and more large-space public service buildings have emerged in the city, such as large-scale gymnasiums, large convention centers, and opera houses. These large-space buildings in general feature wide spans, unique styles, and mostly steel structures. Although steel structural components have good strength under normal atmospheric temperature, when a fire occurs, the heat thus generated may greatly influence the material properties of the steel structural components, in particular mechanical properties. Especially when the temperature of the steel structural component exceeds $550^{\circ} \mathrm{C}$, the ordinary structural steel will lose most of its strength, thus resulting in partial or even whole building collapse. Therefore, the stability of steel structure in a fire has become an important research direction in prevention and mitigation of buildings fires, and the temperature distribution of steel components in a fire is a key issue for stability analysis of steel structure [1-6]. Thus numerous methods for predicting steel temperature development have been proposed. In the developed methods, the heat that steel receives is classified into thermal radiation and heat convection between steel members and hot smoke. These relationships are depicted in (1). As can be seen from (1), thermal radiation and heat convection between steel and smoke directly depend on the hot smoke temperature over steel surface in the fire scene. Therefore, accurate prediction of the smoke temperature curve over the steel surface is most important for accurately predicting the temperature rise of steel components. We have

$$
\begin{gathered}
Q_{g r}=F_{s} \sigma_{0} \varepsilon \times\left[\left(T_{g}+273\right)^{4}-\left(T_{s}+273\right)^{4}\right], \\
Q_{s c}=F_{s} \alpha_{c}\left(T_{g}-T_{s}\right),
\end{gathered}
$$

where $Q_{s c}$ is the smoke convention heat $(\mathrm{W}), Q_{g r}$ is the smoke radiation heat $(\mathrm{W}), \sigma_{0}$ is Stefan-Boltzmann constant, 
$5.67 \times 10^{-8} \mathrm{~W} / \mathrm{m}^{2} \cdot \mathrm{K}^{4}, F_{s}\left(\mathrm{~m}^{2}\right)$ is the steel external surface area per meter, $\varepsilon$ is the effective emissivity of steel, $T_{g}\left({ }^{\circ} \mathrm{C}\right)$ is the smoke temperature, $T_{s}\left({ }^{\circ} \mathrm{C}\right)$ is the steel temperature, and $\alpha_{c}\left(\mathrm{~W} /\left(\mathrm{m}^{2} \cdot{ }^{\circ} \mathrm{C}\right)\right)$ is the convective heat transfer coefficient.

However, the existing prediction methods for the smoke temperature in a fire are mainly concentrated in predicting the temperature distribution of fire smoke in a normal enclosure room fire. For general normal enclosure fires, the temperature distribution is more uniform, and regional models are often used for analysis of smoke temperature. Currently, the temperature standard curves, such as ISO 834 curve, ASTM-E119 temperature curve, external fire temperature curves, and hydrocarbon temperature curve, are commonly used for fire resistance analysis of steel structures and these curves are all obtained from experiment data of normal enclosure fires [7-11], wherein ISO 834 temperature curve is the most commonly used and most representative temperature curve for fire resistance analysis of fire scene structure, and it can be represented as

$$
T_{g}=345 \log (8 t+1)+20,
$$

where $t$ ( $\mathrm{min}$ ) is fire duration. From the above equation it can be found that the smoke temperature reaches $678^{\circ} \mathrm{C}$ 10 minutes after the fire breaks out and reaches $842^{\circ} \mathrm{C} 30$ minutes after the fire breaks out. However, for localized fires in large spaces, due to large building volume and building height, the building interior naturally forms a place which is suitable for smoke and heat storage, and the heat generated by the fire does not accumulate quickly, thus resulting in relatively slow temperature rise of hot smoke in the fire scene [12]. In addition, localized fires in large-space buildings have adequate oxygen supply, and such fires belong to fuelcontrol type combustion, so flashover is rare and the smoke temperature in the fire scene generally does not exceed $600^{\circ} \mathrm{C}$. Secondly, unlike the relatively uniform temperature distribution in normal enclosure room fires, the smoke temperature fields in localized fires in large-space buildings feature a nonuniform distribution. The farther the ceiling is away from the centerline of fire source, the lower smoke temperature is, so the basic assumption of uniform smoke temperature fields in enclosure room fires does not apply to the smoke temperature fields in localized fires in large spaces [13]. To predict the smoke temperature fields in localized fires in large-space buildings, we need to fully consider the nonuniform distribution of fire smoke temperature in the fire scene. In summary, the smoke temperature fields in largespace localized fires are significantly different from those of normal enclosure fires [14]. But till now researches on the smoke temperature fields of localized fires in large-space buildings are still very scanty.

Secondly, unlike the standard fire curve, a natural fire is characterized by three phases: a growing phase, a full developed phase, and a decay phase. It is necessary to evaluate not only the heat effect on the structural resistance during the growing phase and full developed phase but also the high cooling strains in the joint induced by distortional deformation of the heated elements during the decay phase [15]. Therefore the decay phase of a fire is also crucial for the stability of steel structure. Partial structural collapses usually occur in the decay phase of a fire, which showed that a complete temperature curve during the whole process of localized fires in large-space buildings is the basis for a comprehensive analysis of structural fire resistance. But existing studies focused on the smoke temperature development in growing phase and full developed phase, while few studies have been conducted on the temperature development in the decay phase of a fire.

Moreover, in the proposed methods for predicting steel temperature development, the heat that steel receives is classified into thermal radiation and heat convection between steel members and hot smoke as shown in (1). The heat transfer between steel and flame is disregard. In actual large enclosure fires, especially when the flame surrounds the steel members, steel members would receive considerable thermal radiation from flames at the same time, as shown in Figure 1. Thus current methods for calculating heat transfer between steel and localized fire in large spaces are incomprehensive.

In order to study the smoke temperature development and steel temperature development during the whole process of localized fires in large-space buildings, we conducted a fullscale combustion experiment of a bookcase and proposed a fire development model for the whole process of localized fires in large spaces. Based on this fire development model, the technology of FDS (fire dynamic simulation) was applied to investigate the smoke temperature curve in $2 \mathrm{MW}$ to $25 \mathrm{MW}$ fires occurring within a large space with a height of $6 \mathrm{~m}$ to $12 \mathrm{~m}$ and a building area of $1,500 \mathrm{~m}^{2}$ to $10,000 \mathrm{~m}^{2}$. After the inductive analysis of smoke temperature curve, we proposed a temperature rise model for predicting the whole process of localized fires in large spaces. At last, the localized fire source in large space is treated as one point fire source to evaluate the flame net heat flux to steel and a modified model of steel temperature development in localized fire is built.

\section{Development Model of Localized Fires in Large Spaces}

2.1. Full-Scale Experiment. In order to study the development model of localized fires in large spaces, we conducted a fullscale combustion characteristic experiment in a large space. The experiment selected a representative wooden bookcase as the combustible material and recorded the mass loss rate of the bookcase in the experiment. In the experiment the bookcase weighs $46.5 \mathrm{~kg}$ and is evenly filled with $10 \mathrm{~kg}$ of paper sheets inside. The calorific values of wood and paper indicated by the SFPE (Society of Fire Protection Engineers) manual are, respectively, $17 \mathrm{MJ} / \mathrm{kg}$ to $20 \mathrm{MJ} / \mathrm{kg}$ and $16 \mathrm{MJ} / \mathrm{kg}$ to $20 \mathrm{MJ} / \mathrm{kg}$ [16]. The mean of the calorific values of paper and wood was used as the actual calorific value of the wood and the paper, and the weighted average method was applied to determine the average combustion calorific value of bookcase as $18.4 \mathrm{MJ} / \mathrm{kg}$.

The scenes of bookcase combustion in the experiment are shown in Figure 2. As seen in Figure 2, a typical bookcase fire within a large space has distinctively exhibited growing phase, full developed phase (steady phase), and decay phase. 


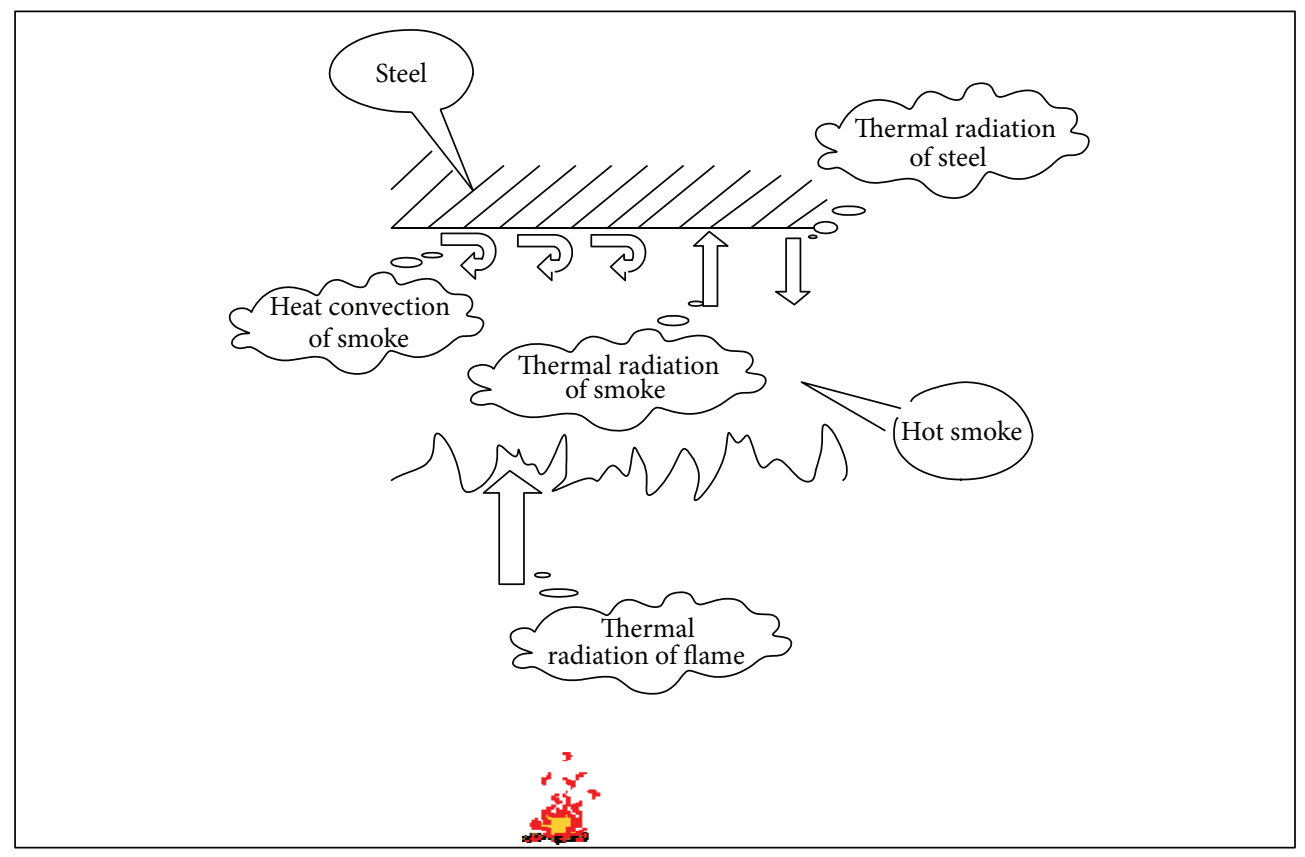

FIGURE 1: Energy balance of steel components in fire.

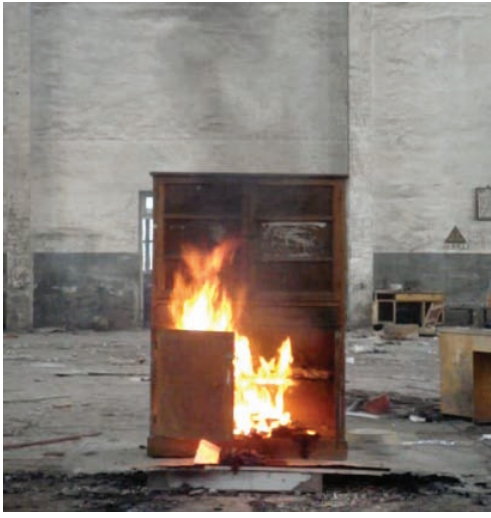

Growing phase

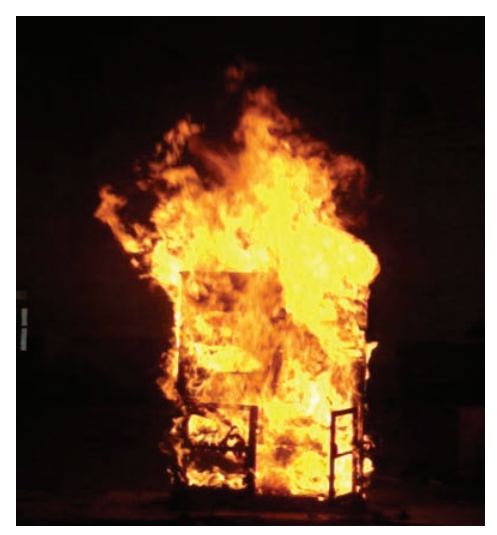

Full developed phase

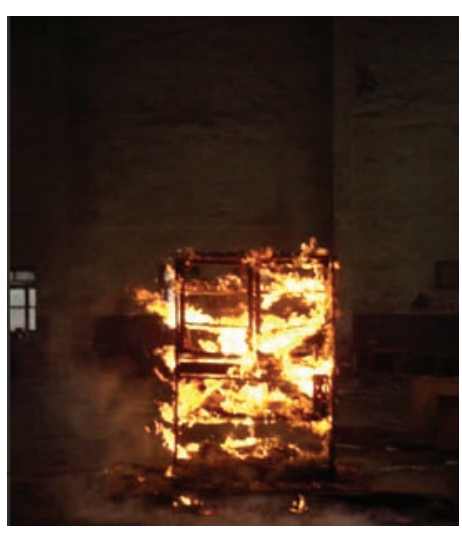

Decay phase

Figure 2: Scenes of bookcase combustion.

The mass loss rate during the process of bookcase combustion is shown as the curve in Figure 3. According to Figure 3, the mass loss rate during the process of bookcase combustion shows stages, respectively, of increase, relative stability, and linear decrease. The three stages of mass loss rate are consistent with the combustion stages of a fire.

The growing phase determines the early development pace of a fire and is an important part of fire model. It can be found from the fitting of mass loss rate at the growing phase of the bookcase fire that the mass loss rate at the growing phase is proportional to the square value of the time $t$, as shown in Figure 4:

$$
\frac{d m}{d t}=0.00188 t^{2}
$$

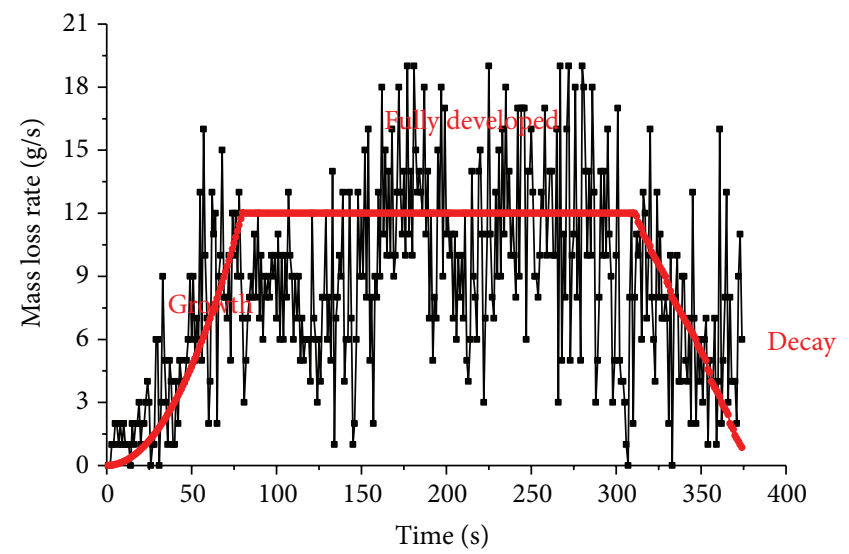

FIGURE 3: Schematic diagram of three phases in fire development. 
TABLE 1: Fire growth coefficient $\alpha$.

\begin{tabular}{lcc}
\hline Combustible material & Fire classification & $\alpha /\left(\mathrm{kW} / \mathrm{s}^{2}\right)$ \\
\hline Waste paper basket & Slow fire & 0.0029 \\
Noncotton products/polyester mattresses/TV sets/foam rubber pillows & Medium fire & 0.0117 \\
Plastic foam/stacked wooden boards/mail pouches filled with mails & Fast fire & 0.0469 \\
Methanol/fastburning upholstered chairs/Christmas tree & Ultrafast fire & 0.1876 \\
\hline
\end{tabular}

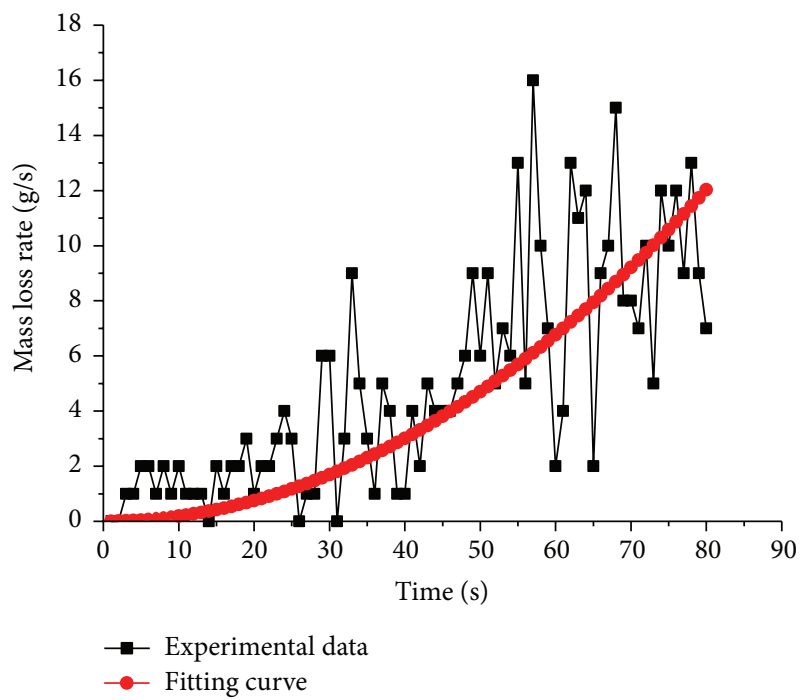

FIGURE 4: Schematic diagram of variation curve of mass loss rate at fire growing phase.

Assuming that the bookcase is in complete combustion, that is, combustion efficiency is 1 , the heat release rate at the growing phase of the fire can be expressed as

$$
Q=\frac{d m}{d t} \times \Delta H=18.4 \times 0.00188 t^{2}=0.0346 t^{2}
$$

where $\Delta H$ is the calorific value of the bookcase $(\mathrm{kJ} / \mathrm{kg})$.

2.2. Fire Development Model. As shown in the experiment, a typical localized fire in a large space generally experiences its growing phase, full developed phase (steady phase), and decay phase. For the growing phase, the fire spreads outward from a fire source point. Studies have shown that, with sufficient oxygen supply, the flames will spread horizontally along the combustible materials at a constant rate, and that is

$$
L=v t
$$

where $L(\mathrm{~m})$ is the flame front position at time $t ; v(\mathrm{~m} / \mathrm{s})$ is the flame spread rate. In most cases, the flames evenly spread to the surroundings, and the burned area of combustible materials can be approximated as round in shape. Therefore, at the growing phase of the fire, the heat release rate can be expressed as

$$
Q=A q=\pi L^{2} q=\pi q v^{2} t^{2}
$$

where $q\left(\mathrm{~kW} / \mathrm{m}^{2}\right)$ is the heat release rate per unit area of the fire source and $A\left(\mathrm{~m}^{2}\right)$ is the area of the fire source. $q$ and $v$ are constant values for an ideal fire model, which satisfies $\pi q v^{2}=\alpha$, where $\alpha$ is fire growth coefficient $\left(\mathrm{kW} / \mathrm{s}^{2}\right)$ and then (6) can be transformed into the following equation:

$$
Q=\alpha t^{2}
$$

As seen in (7), for an ideal localized fire in a large space, the heat release rate in a fire can be expressed as a function of time $t^{2}$. This conclusion is consistent with the heat release rate of the bookcase experiment at the growing phase: $Q=0.0346 t^{2}$. In other words, the ideal growing phase of a localized fire in a large space fits the $t^{2}$ fire model, wherein the fire growth coefficient $\alpha$ characterizes the spread speed of a fire. According to NFPA 204: Standard for Smoke and Heat Venting issued by the National Fire Protection Association of USA, fire growing phase can be further divided into slow fire, medium fire, fast fire, and ultrafast fire [17]. Table 1 shows the corresponding relation between the fire growth coefficient $\alpha$ and the sample materials specified in NFPA standard. For most localized fires in large-space buildings, the fire growth coefficient generally varies in the range between medium fire and fast fire. We can refer to the bookcase combustion experiment, in which the fire growth coefficient $\alpha$ at the growing phase is $0.0346 \mathrm{~kW} / \mathrm{s}^{2}$, a coefficient varying in a range between medium and fast fire likewise. This paper proposed that for localized fires in large-space buildings full of wooden combustible materials the growth phase of a fire could be simplified into the $t^{2}$ fire model with a fire development coefficient of $0.0346 \mathrm{~kW} / \mathrm{s}^{2}$.

With the development of a fire, when all the combustible materials get burned, the heat release rate of the fire will reach its maximum value and remain steady for a while and by this time the fire enters the full developed phase also known as the steady phase. In this case, the maximum heat release rate of the fire is constant, which can be expressed as

$$
Q=Q_{\max }=q A_{\max }
$$

where $A_{\max }\left(\mathrm{m}^{2}\right)$ is the largest burned area of the localized fire and $Q_{\max }(\mathrm{kW})$ is the maximum heat release rate of the fire. With the further consumption of combustibles, the fire gradually enters the decay phase. The experiments showed that the heat release rate at the fire decay phase exhibited an approximate linear decreasing trend, which is consistent with the conclusion of the bookcase combustion experiment provided in Section 2.1. For fires following a linear decline trend, the heat release rate curve at the fire decay phase can be expressed as

$$
Q=\frac{t_{s}}{t_{s}-t_{d}} Q_{\max }-\frac{t}{t_{s}-t_{d}} Q_{\max },
$$



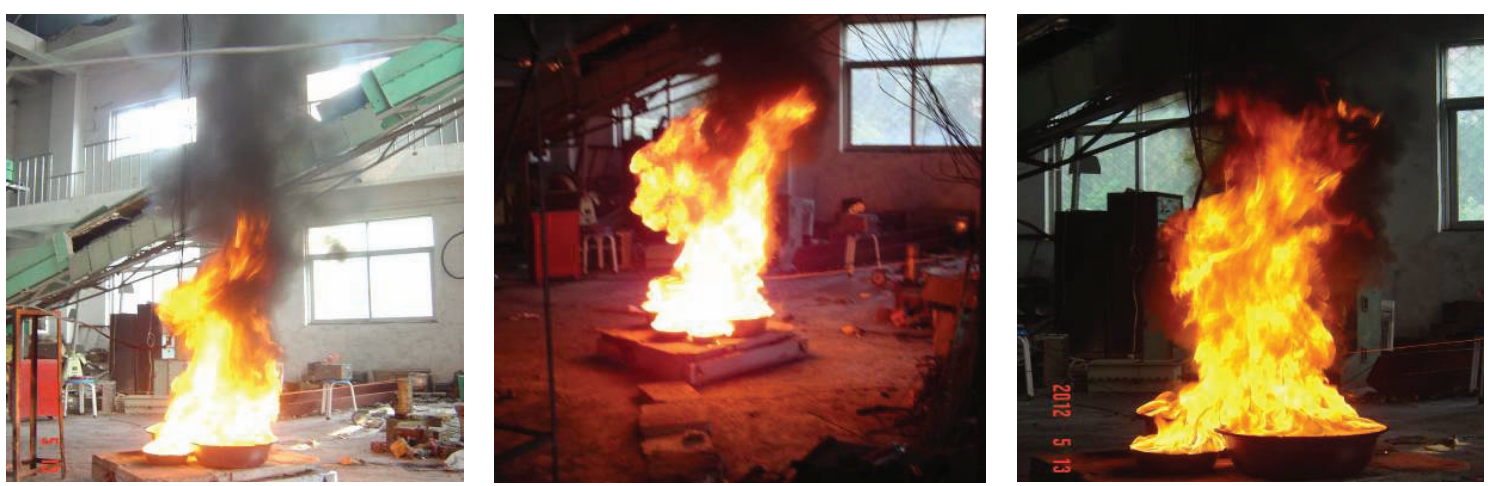

FIGURE 5: Localized fire experiments in a large-space building.

where $t_{s}(\mathrm{~s})$ is total time of the whole process of a fire; $t_{d}(\mathrm{~s})$ is time when the fire enters the decay phase.

The simultaneous equations of (7)-(9) determine the development model for the whole process of localized fires in large spaces as follows:

$$
\begin{gathered}
Q=\alpha t^{2}, \quad 0 \leq t \leq t_{g}, \\
Q=q A_{\max }, \quad t_{g} \leq t \leq t_{d}, \\
Q=\frac{t_{s}}{t_{s}-t_{d}} Q_{\max }-\frac{t}{t_{s}-t_{d}} Q_{\max }, \quad t_{d} \leq t \leq t_{s},
\end{gathered}
$$

where $t_{g}=\sqrt{Q_{\max } / \alpha}(\mathrm{s})$ is the time when the fire enters the full developed phase (steady phase).

DD240 research has shown that when $80 \%$ of the fire loads have been consumed, the fire enters the decay phase [18]. In other words, the decay phase of the fire altogether consumes $20 \%$ of the fire loads, while the growing phase and the steady phase of the fire consume $80 \%$ of the fire loads, which can be expressed as follows:

$$
\begin{gathered}
0.2 F_{L}=\int_{t d}^{t s} \frac{t_{s}}{t_{s}-t_{d}} Q_{\max }-\frac{t}{t_{s}-t_{d}} Q_{\max } d t=\frac{Q_{\max }}{2}\left(t_{s}-t_{d}\right), \\
0.8 F_{L}=\int_{0}^{t_{g}} \alpha t^{2} d t+\int_{t_{g}}^{t_{d}} Q_{\max } d t=\frac{\alpha}{3} t_{g}^{3}+\left(t_{d}-t_{g}\right) Q_{\max },
\end{gathered}
$$

where $F_{L}(\mathrm{MJ})$ is the total fire load and the solution to $t_{d}$ in the simultaneous equations of (11) is

$$
t_{d}=\frac{6 t_{s}+2 t_{g}}{9}=\frac{6 t_{s}+2 \sqrt{Q_{\max } / \alpha}}{9} .
$$

As can be concluded from the above analysis, when the growth coefficient, the maximum heat release rate, and the duration of the fire are fixed, the mathematical models for the growing phase, the full developed phase (steady phase), and the decay phase of the fire can be determined. For the analysis of structural fire resistance, fire duration is generally defined as structural fire resistance, and the growth coefficient and the maximum heat release rate of the fire are decided by the designer according to architectural uses, fire load, type of combustibles, and so forth.

\section{LES of Smoke Temperature of Localized Fire in Large Spaces}

3.1. FDS Large Eddy Simulation Technology. In order to study the smoke temperature fields in fire scenes with different heat release rates, different building areas, and building heights, a series of full-scale fire experiments needs to be carried out for demonstration. Performing dozens of full-scale fire experiments not only is costly and difficult to operate but also can cause environment pollution, and, furthermore, the experiment results are often affected by experiment environment and laboratory instruments. The FDS technology based on large eddy simulation technology has increased the potential to solve such problems [19]. FDS technology is applied based on the FDS software platform which is a professional software launched by NIST (National Institute of Standards and Technology) for fire smoke migration analysis. An approximate form of the Navier-Stokes equations appropriate for low Mach number applications is used in the model of FDS. The approximation involves the filtering out of acoustic waves while allowing for large variations in temperature and density. When it comes to localized fires in large-space buildings, the problems of heat and mass transfer in FDS model fit the fundamental conservation equations, such as conservation of mass, conservation of momentum, transport of sensible enthalpy, and equation of state for a perfect gas [18].

3.2. Accuracy Analysis. Scientific studies have shown that in the case of scientific meshing, FDS large eddy simulation technology can accurately predict the smoke temperature distribution in fire scenes [20,21]. To further demonstrate the accuracy of FDS large eddy simulation technology, the authors performed two full-scale localized fire experiments in a large-space building which is 11 meters high, 20 meters long, and 14 meters wide. Diesel fuel as pool fire was placed on weighing sensor and the camera captured images of the flame and smoke layer. Thermocouples were disposed under the ceiling $4 \mathrm{~m}$ away from the fire source to measure the smoke temperature, as shown in Figure 5. And the measuring range of thermocouple is $0^{\circ} \mathrm{C} \sim 200^{\circ} \mathrm{C}$ with $0.4 \%$ allowable error. A comparison of the experiment data of fire smoke temperature and the prediction result obtained by application of FDS large 


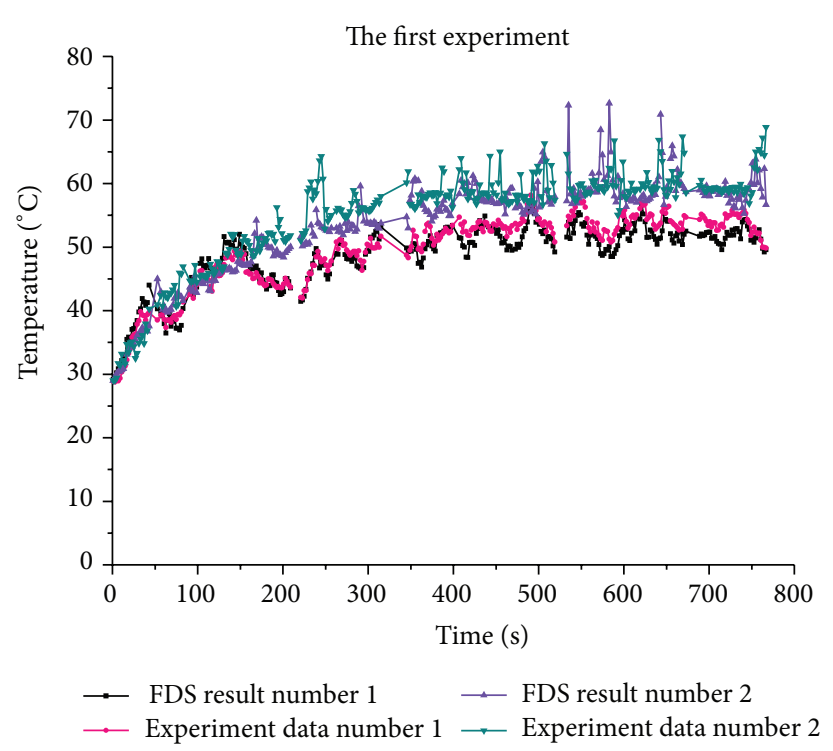

(a)

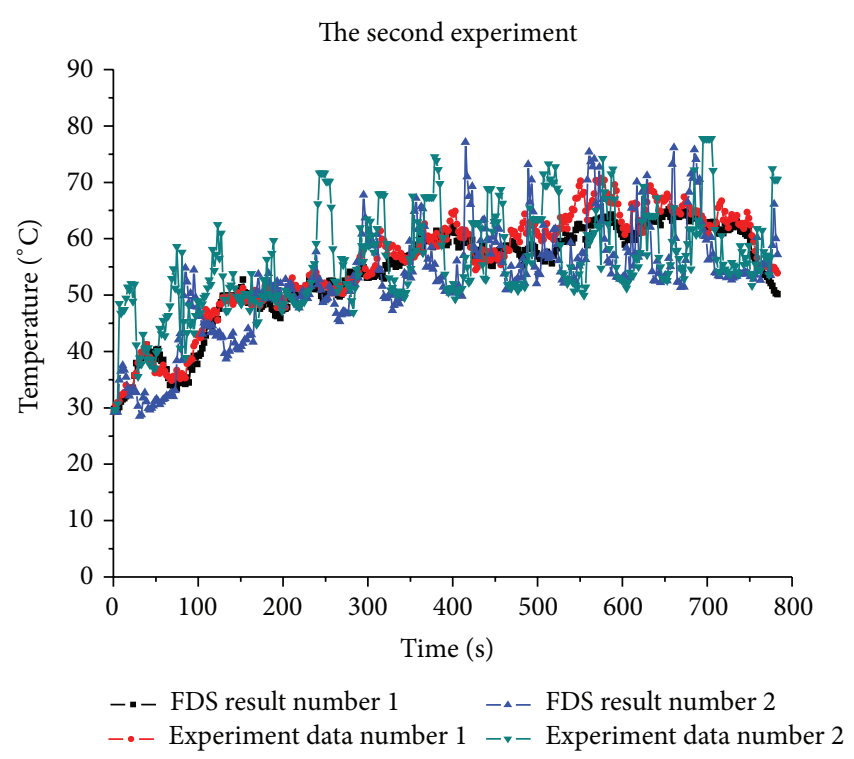

(b)

FIGURE 6: Comparison diagrams of the experimental values of fire smoke temperatures and the prediction values obtained by FDS.

eddy simulation are shown in Figure 6. It can also be seen in Figure 6 that by using FDS large eddy simulation technology, the distribution of smoke temperature fields of localized fires in large spaces can be accurately predicted [22].

\section{Smoke Temperature Fields of Localized Fires in Large Space}

Using FDS large eddy simulation technology, this study investigated the distribution of smoke temperature fields in tens of fire scenes with different building heights ( $6 \mathrm{~m}$ to $12 \mathrm{~m}$ ), building areas $\left(1,500 \mathrm{~m}^{2}\right.$ to $\left.10,000 \mathrm{~m}^{2}\right)$, and fire powers (2 MW to $25 \mathrm{MW}$ ). FDS is a computational fluid dynamics (CFD) model of fire-driven fluid flow. The model solves numerically a form of the Navier-Stokes equations appropriate for lowspeed, thermally driven flow with an emphasis on smoke and heat transport from fires. The partial derivatives of the conservation equations of mass, momentum, and energy are approximated as finite differences, and the solution is updated in time on a three-dimensional, rectilinear grid. Thermal radiation is computed using a finite volume technique on the same grid as the flow solver. In simulation, large eddy simulation model was used; mesh size of model is $0.25 \mathrm{~m} \times$ $0.25 \mathrm{~m} \times 0.25 \mathrm{~m}$. Therein, the fire development model in the fire scenes refers to the settings provided in Section 2.2. The fire growth coefficient is set as $0.0346 \mathrm{~kW} / \mathrm{s}^{2}$ by reference to the bookcase fire experiment, the heat release rate per unit area of the fire is set as $500 \mathrm{~kW} / \mathrm{m}^{2}$, and the simulated fire duration is $2 \mathrm{~h}$. The simulation results showed that, in spite of different temperature rise curves of fire smoke for various fire scenes, the overall variation trends of the temperature rise curves are identical and follow a certain rule. For largespace buildings with a height greater than $6 \mathrm{~m}$ and a building area more than $1500 \mathrm{~m}^{2}$, the building height and building area have relatively little effect on the curve trend of fire smoke, while the power of fire source can significantly influence the curve trend of fire smoke.

4.1. Basic Equations. By observing and analyzing temperature rise curves of localized fires in large spaces, the study established the smoke temperature curve model for the whole development process of localized fires:

$$
\begin{aligned}
& T_{g}=T_{m} \times e^{-\left(\ln t-\ln t_{d}\right)^{2} / \omega_{1}}+T_{0}, \quad t \leq t_{d}, \\
& T_{g}=T_{m} \times e^{-\left(\ln t-\ln t_{d}\right)^{2} / \omega_{2}}+T_{0}, \quad t \geq t_{d},
\end{aligned}
$$

where $T_{g}\left({ }^{\circ} \mathrm{C}\right)$ is the smoke temperature that changes with time $t(\mathrm{~s}) ; t_{d}(\mathrm{~s})$ is the time when the fire enters the decay phase, determined by $(12) ; T_{m}\left({ }^{\circ} \mathrm{C}\right)$ is the maximum value of smoke temperature at a certain location under the ceiling during the whole process of the fire; $T_{0}\left({ }^{\circ} \mathrm{C}\right)$ is the initial environment temperature. $\omega_{1}$ and $\omega_{2}$ are the curve shape coefficients of fire smoke during the development phase (fire growing phase and steady phase) and decay phase of the fire, respectively.

In the prediction model of smoke temperature curve during the whole development process of localized fires in large spaces (e.g., (13)), the maximum value of smoke temperature $T_{m}$ and curve shape coefficients $\omega_{1}$ and $\omega_{2}$ are two leading factors in determining the curve trend of fire smoke. Figure 7 shows how different maximum values of smoke temperatures influence the temperature curves with identical $\omega_{1}, \omega_{2}, t_{d}$, and $T_{0}$. Figure 8 , on the other hand, shows how different shape coefficients influence the curves of fire smoke with identical $T_{m}, t_{d}$, and $T_{0}$. As seen in Figure 8 , the shape coefficients $\omega_{1}$ and $\omega_{2}$ have determined the shapes of the temperature curves. The greater $\omega_{1}$ is, the faster the smoke 


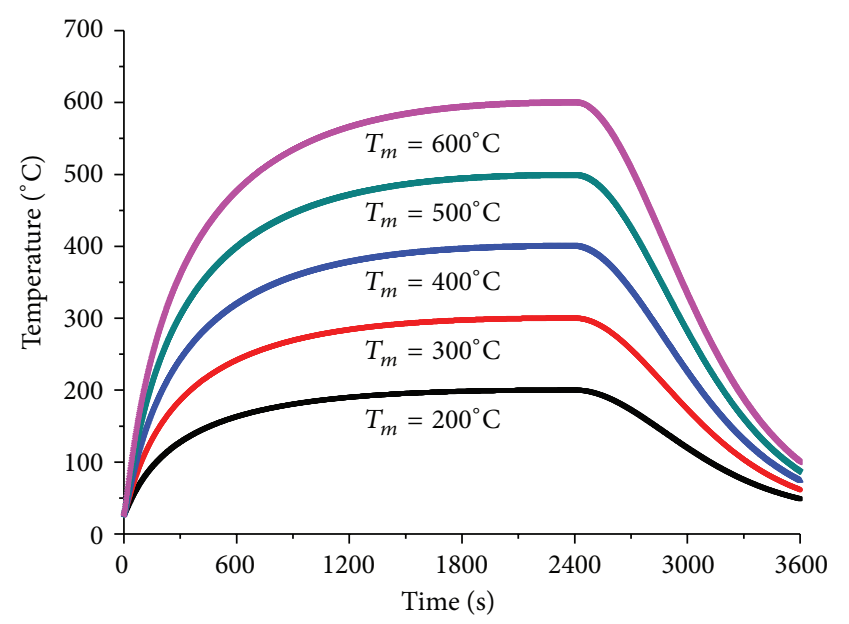

FIGURE 7: Effect of maximum temperatures on the temperature curves (with identical $\varrho_{1}, \omega_{2}$, and $T_{0}$ ).

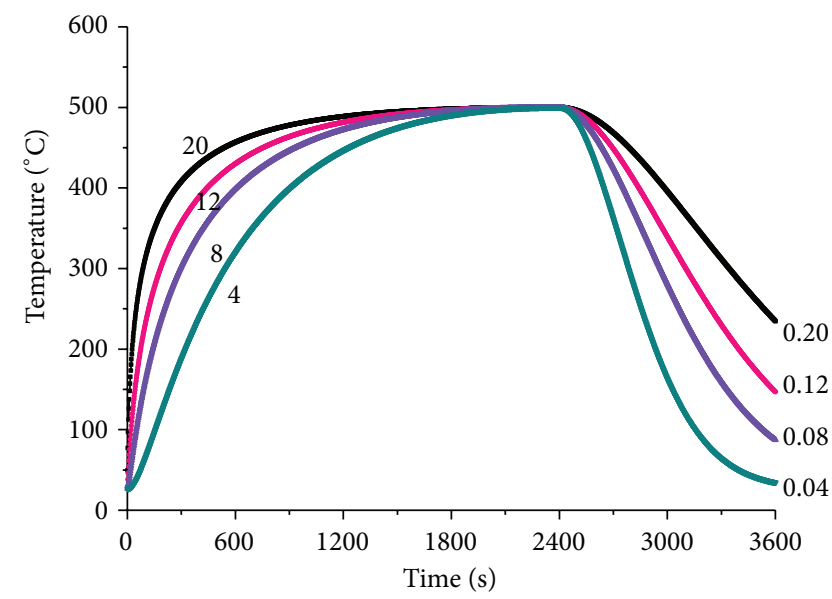

Figure 8: Effect of shape coefficients on the temperature curves (with identical $t_{m}, T_{m}$, and $T_{0}$ ).

temperature rises; the greater $\omega_{2}$ is, the slower the smoke temperature drops.

4.2. Shape Coefficient. Shape coefficient is a key to determining the temperature curves of fire smoke. After the simulation analysis of fire scenarios with different fire powers, building heights, and building areas, the authors found that for largespace buildings with a height greater than $6 \mathrm{~m}$ and a building area more than $1500 \mathrm{~m}^{2}$, building height and building area have exerted relatively little impact on the shape coefficient, whereas the power of fire source can significantly influence the value of the shape coefficient. Based on the inductive analysis of the temperature curves of fire smoke in different fire scenarios, the authors proposed the recommended values of the shape coefficients for a typical localized fire (the fire growth coefficient is $0.0346 \mathrm{~kW} / \mathrm{s}^{2}$ ) in a large-space building (with a height greater than $6 \mathrm{~m}$ and a building area more than $1500 \mathrm{~m}^{2}$ ). For fire power of less than $5 \mathrm{MW}$, the recommended value of shape coefficient at the development phase and the steady phase of the fire is 8 , and that at the decay phase is 0.08 . For fire power of $5 \mathrm{MW}$ to $25 \mathrm{MW}$, the recommended value of shape coefficient at the development phase and the steady phase of the fire is 6 , and that at the decay phase is 0.08 .

Figure 9 is a comparison diagram of the temperature prediction curves of fire smoke and the results of FDS large eddy simulation in some fire scenarios (three measurement points: point number 1 is $4 \mathrm{~m}$ away from centerline of fire source, point number 2 is $8 \mathrm{~m}$ away from centerline of fire source, point number 3 is $12 \mathrm{~m}$ away from centerline of fire source) with no regard for the maximum temperature of fire smoke based on recommended shape coefficients. It can be seen from the comparison that, when using the appropriate shape coefficient, the curves based on the prediction modes can accurately predict the temperature field of fire smoke of a localized fire in a large-space building.

4.3. Maximum Value of Smoke Temperature. As shown in Figure 10, when a localized fire breaks out in a large space, after the smoke plume impinges on the ceiling, the ceiling surface causes the smoke plume to turn and move horizontally under the ceiling to other areas of the building remote from the fire position. Figure 11 is a typical temperature distribution of smoke layer below the ceiling. From Figure 11 it can be seen that the temperature of smoke layer gradually decreases outward along the fire source, the smoke temperature reaches its maximum at the plume centerline, and smoke temperatures are relatively uniformly distributed within a certain range around the plume centerline (inside the black circle in Figure 11), and, furthermore, the smoke temperatures away from the fire source show a significant decreasing trend. Therefore, the smoke temperatures under the ceiling exhibit a nonuniform distribution, and the smoke temperature is correlated with factors such as the power of the fire source, building characteristics, and the horizontal distance between fire smoke and the center of the fire source.

Professor Du from Nanjing University of Science and Technology in China studied the maximum value of smoke temperature inside the building for a $2 \mathrm{MW}$ to $25 \mathrm{MW}$ fire in a large-space building with a height of $4 \mathrm{~m}$ to $20 \mathrm{~m}$ and an area of $500 \mathrm{~m}^{2}$ to $600 \mathrm{~m}^{2}$. It has been found that the maximum value of the temperature of fire smoke at a location below the ceiling can be expressed as [23]

$$
T_{m}=T_{g}^{\max } \times k_{s m}
$$

where $k_{s m}$ is the temperature correction coefficient and $T_{g}^{\max }$ $\left({ }^{\circ} \mathrm{C}\right)$ is the maximum value of smoke temperature under the ceiling right above the fire source. $T_{g}^{\max }$ is dependent upon factors such as fire power, building height, and building area. It has been found from Professor Du's fitting analysis of the data that

$$
\begin{aligned}
T_{g}^{\max }= & \left(\frac{Q_{\max }}{50}+80\right)-\left(\frac{4 Q_{\max }}{10000}+3\right) H \\
& +\frac{\left(52 Q_{\max } / 1000+598\right) \times 10^{2}}{A},
\end{aligned}
$$




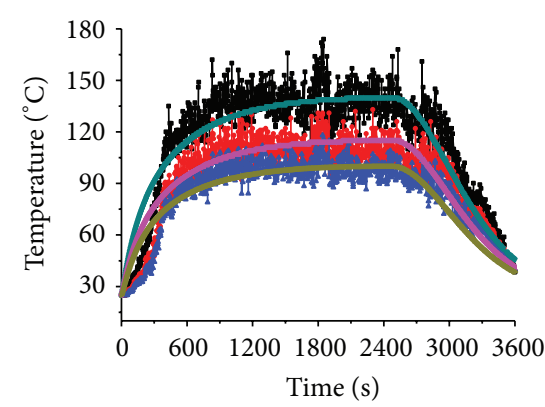

$$
\begin{aligned}
& \rightarrow \underset{\text { FDS result }}{\text { number } 1} \rightarrow \begin{array}{c}
\text { Predicted value } \\
\text { number } 1
\end{array} \\
& \rightarrow \begin{array}{c}
\text { FDS result } \\
\text { number } 2 \\
\text { Predicted value } \\
\text { number } 2
\end{array} \\
& \rightarrow \underset{\text { FDS result }}{\text { number } 3} \rightarrow \begin{array}{c}
\text { Predicted value } \\
\text { number } 3
\end{array} \\
& H=6 \mathrm{~m} ; Q_{\max }=5 \mathrm{MW} ; S=3000 \mathrm{~m}^{2}
\end{aligned}
$$

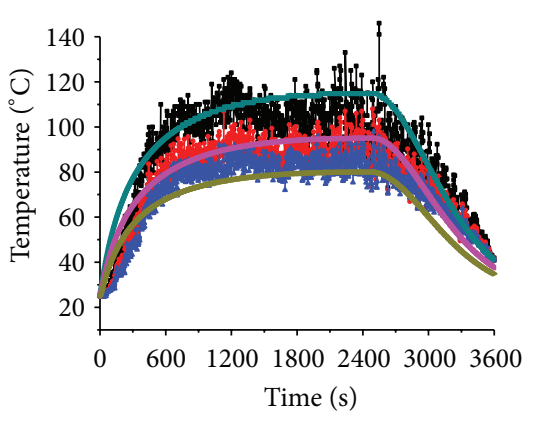

$$
\begin{aligned}
& \rightarrow \underset{\text { FDS result } \rightarrow}{\text { number } 1} \begin{array}{c}
\text { Predicted value } \\
\text { number } 1
\end{array} \\
& \rightarrow \begin{array}{c}
\text { FDS result } \\
\text { number } 2 \\
\text { Predicted value } \\
\text { number } 2
\end{array} \\
& \text { FDS result } \\
& \text { number } 3 \\
& H=12 \mathrm{~m} ; Q_{\max }=5 \mathrm{MW} ; S=3000 \mathrm{~m}^{2}
\end{aligned}
$$

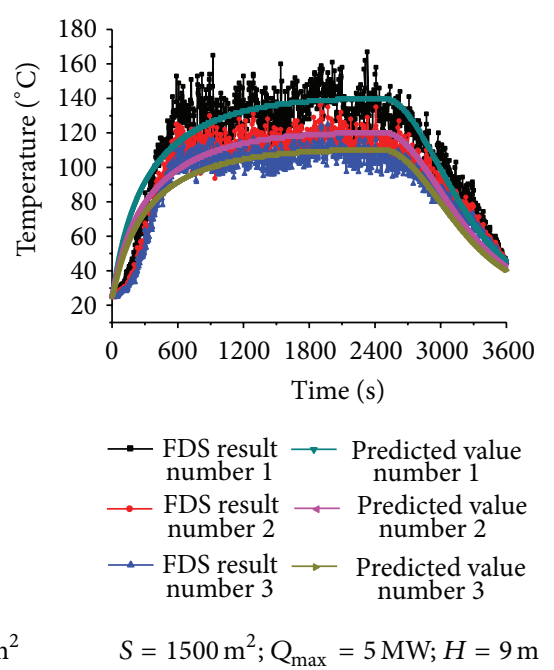

(a)
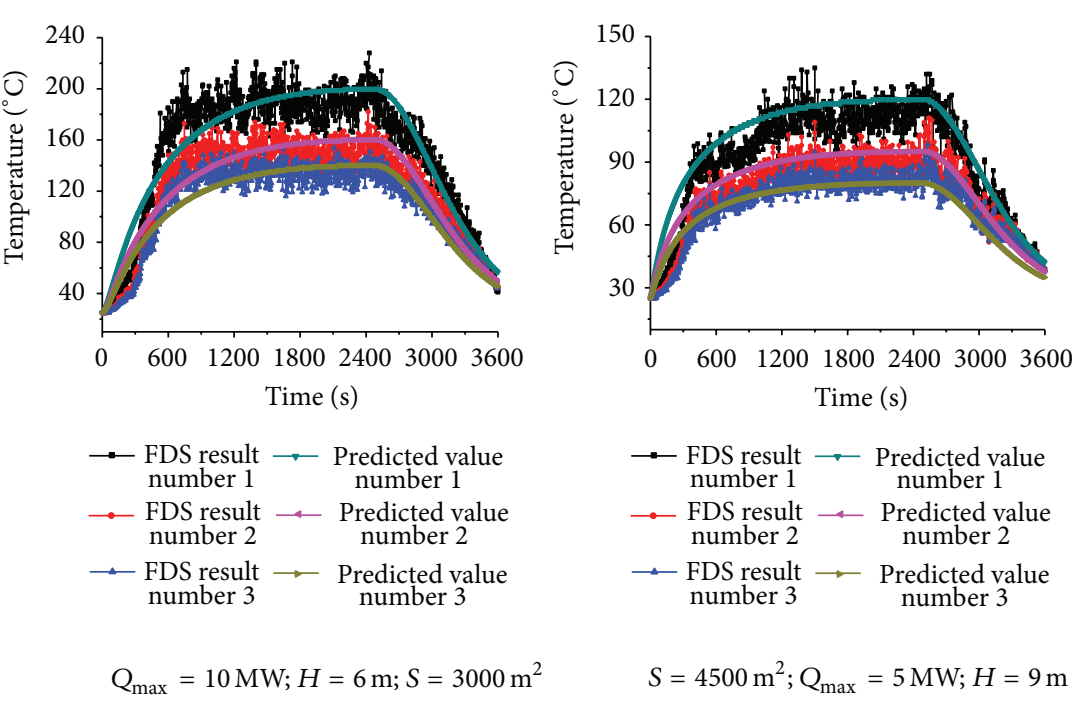

(b)

FIGURE 9: Comparison diagrams of the predicted curves and the results of FDS large eddy simulation. In the figure, $S\left(\mathrm{~m}^{2}\right)$ is the area, $H(\mathrm{~m})$ is the building height, and $Q_{\max }(\mathrm{MW})$ is the maximum value of fire power.

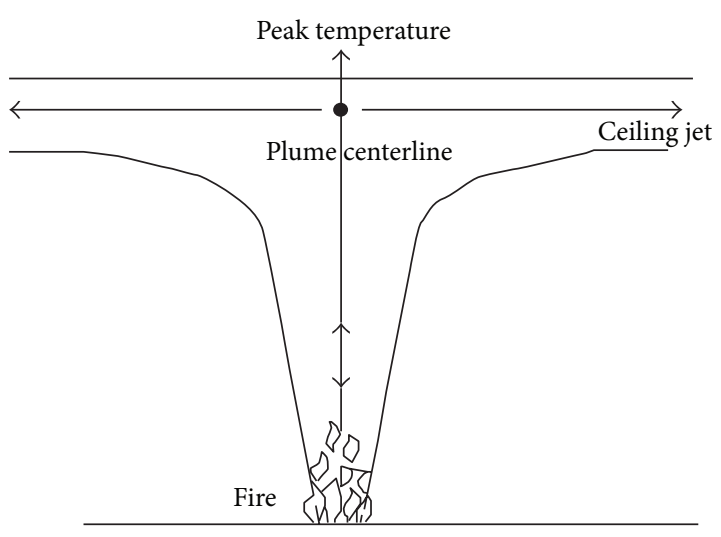

FIGURE 10: Fire smoke migrations in a localized fire. where $A\left(\mathrm{~m}^{2}\right)$ is building area and $H(\mathrm{~m})$ is building height. The temperature correction coefficient $k_{s m}$ is correlated with the horizontal distance between fire smoke and the center of the fire source. Professor Du has presented the empirical equation of the temperature correction coefficient:

$$
\begin{gathered}
k_{s m}=\eta+(1-\eta) e^{(D / 2-x) / 7}, \quad x \geq \frac{D}{2}, \\
k_{s m}=1, \quad x \leq \frac{D}{2},
\end{gathered}
$$

where $D(\mathrm{~m})$ is the diameter of the fire source and $D=$ $\sqrt{4 Q / \pi q} ; x(\mathrm{~m})$ is the horizontal distance from the center of the fire source; $\eta$ is the correction coefficient which depends upon the factors of building height and area, as shown in Table 2. 


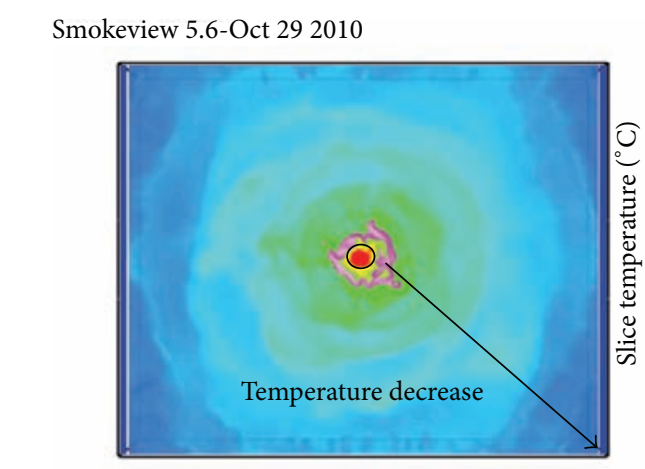

Frame: 111

Time: 333.0

$333 \mathrm{~s}$ after the fire breaks out

(a)
Smokeview 5.6-Oct 292010

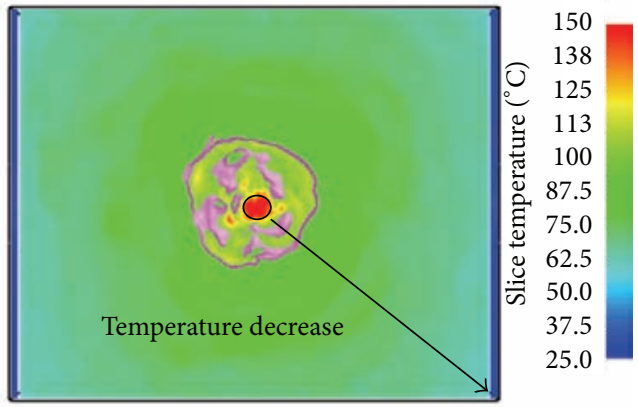

Frame: 217

Time: 651.0

(b)

FIGURE 11: Temperature distribution of fire smoke layer of a typical building fire in a large space.

TABLE 2: Value for $\eta$.

\begin{tabular}{lccccc}
\hline Building area & \multicolumn{5}{c}{ Building height $(\mathrm{m})$} \\
$\left(\mathrm{m}^{2}\right)$ & 6 & 9 & 12 & 15 & 20 \\
\hline 500 & 0.60 & 0.65 & 0.70 & 0.80 & 0.85 \\
1000 & 0.50 & 0.55 & 0.60 & 0.70 & 0.75 \\
3000 & 0.40 & 0.45 & 0.50 & 0.55 & 0.60 \\
6000 & 0.25 & 0.30 & 0.40 & 0.45 & 0.50 \\
\hline
\end{tabular}

\section{The Modified Model of Steel Temperature Development in Localized Fire}

5.1. The Energy Balance Equation. As shown in Figure 1, a localized fire in large enclosure transfers smoke radiation, smoke convection, and flame radiation heat to the steel as shown in (17). Although the steel member can also exchange heat with other structural parts which are at different temperatures in the room by thermal radiation, the radiation shape factor and temperature difference between steel and other structural parts are lower than fire smoke. Thus exchanged heat between steel member and other structural parts could be neglected on the predicted structural temperature evolution. It is assumed that the steel members are black bodies and there are no temperature gradients along or across the components. The assumption is conveniently made to study the heat transfer between the steel and the localized fire:

$$
Q_{s}=Q_{g r}+Q_{f r}+Q_{s c}
$$

where $Q_{s}$ is the net heat transfer rate (W), $Q_{g r}$ is the smoke radiation heat transfer rate $(\mathrm{W}), Q_{f r}$ is the flame radiation heat transfer rate $(\mathrm{W})$, and $Q_{s c}$ is the smoke convention heat transfer rate $(\mathrm{W})$.

Meanwhile steel is a good conductor with less than 0.1 Biot number, so we can use the lumped heat capacity method to model the temperature development of steel members in fire. The energy balance equation is built as follows.

$$
Q_{s}=V_{s} \rho_{s} C_{s} \frac{d T_{s}}{d t}
$$

where $\rho_{s}$ is the density of steel $\left(\mathrm{kg} \cdot \mathrm{m}^{-3}\right), T_{s}$ is the steel temperature $\left({ }^{\circ} \mathrm{C}\right)$, and $C_{s}$ is the specific heat of steel $\left(\mathrm{J} /\left(\mathrm{kg} \cdot{ }^{\circ} \mathrm{C}\right)\right)$.

5.2. The Smoke Net Heat Flux to Steel. As discussed above, the smoke net heat flux to steel contains two parts: radiation heat flux and convention heat flux. And as stated in previous investigations, radiation heat flux and convention heat flux from smoke could be separately evaluated by (1).

5.3. The Flame Net Heat Flux to Steel. Localized fire in large space could be treated as one point source located at the center of fire flame stated in the SFPE handbook, and it is customary to model the flame by a point source to predict the thermal radiation field of flames. The point source releases heat to the global surrounding and the incident radiation heat flux one target received could be evaluated as follows:

$$
q=\frac{Q}{12 \pi R^{2}}
$$

where $R$ is the distance from the point source, $p$, to the target $(\mathrm{m})$. The $p$ point is at the center of the fire surface and at the midheight of the flame. Flame height is calculated using $H_{f}=$ $-1.02 D+0.235 Q^{2 / 5}$.

Not all the steel external surface could receive heat radiation flux from flame, so one shape factor $\gamma$ should be proposed to correct the effective surface area. Meanwhile, part of incident radiation heat flux would be absorbed by the smoke layer, so the radiation flux the steel member received from flame should be corrected as $\left(1-a_{g}\right) q$, where $\alpha_{g}$ is the absorptivity of smoke layer. 
Thus the effective flame radiation flux which the steel member received through the smoke layer in fire could be evaluated by the following equation:

$$
Q_{f r}=\frac{F_{s} \gamma Q \times\left(1-a_{g}\right)}{12 \pi R^{2}} .
$$

5.4. The Model for the Steel Temperature Development in Localized Fire. Based on the discussion above, the steel temperature development in localized fire could be evaluated by the following equation:

$$
\begin{array}{r}
\Delta T=\frac{F_{s} \Delta t}{V_{s} \rho_{s} C_{s}}\left[\sigma_{0} \varepsilon\left(\left(T_{g}+273\right)^{4}-\left(T_{s}+273\right)^{4}\right)\right. \\
\left.+\alpha_{c}\left(T_{g}-T_{s}\right)+\frac{\gamma Q\left(1-a_{g}\right)}{12 \pi R^{2}}\right] .
\end{array}
$$

\section{Case Study}

To illustrate application of the new approach given above to predict the smoke temperature and steel temperature, an example for giving fire scenario is provided. A localized fire broke out in a large-space building with a height of $6 \mathrm{~m}$ and a building area of $3000 \mathrm{~m}^{2}$. The fire growth coefficient is $0.0346 \mathrm{~kW} / \mathrm{s}^{2}$, the heat release rate per unit area is $500 \mathrm{~kW} / \mathrm{m}^{2}$, and the maximum heat release rate is $7.5 \mathrm{MW}$. The fire lasted for $2 \mathrm{~h}$ and the ambient temperature is $20^{\circ} \mathrm{C}$. Now the new approaches are applied to predict the smoke temperature curve and steel temperature curve under the ceiling at a distance of $12 \mathrm{~m}$ from the centerline of the fire source. And the basic parameters of steel components are $F_{s} / V_{s}=35 \mathrm{~m}^{-1}, \varepsilon=0.8, \alpha_{g}=0.5, \alpha_{c}=25, \rho_{s}=7850 \mathrm{~kg} \cdot \mathrm{m}^{-3}$, $\gamma=0.5$, and $C_{s}=480 \mathrm{~J} /(\mathrm{kg} \cdot \mathrm{K})$.

First, according to (9), (10), and (12), we decide on the fire development model, as follows:

$$
\begin{gathered}
Q=0.0346 t^{2}, \quad 0 \leq t \leq 466, \\
Q=7500, \quad 466 \leq t \leq 2504, \\
Q=24635-6.84 t, \quad 2504 \leq t \leq 3600 .
\end{gathered}
$$

According to (15), we can determine the maximum value of the smoke temperature under the ceiling right above the fire source:

$$
\begin{aligned}
T_{g}^{\max }= & \left(\frac{7500}{50}+80\right)-\left(\frac{4 \times 7500}{10000}+3\right) \times 6 \\
& +\frac{(52 \times 7500 / 1000+598) \times 10^{2}}{3000}=227\left({ }^{\circ} \mathrm{C}\right) .
\end{aligned}
$$

According to (16) and Table 2, we can further determine the temperature correction coefficient $k_{s m}$ :

$$
k_{s m}=0.4+(1-0.4) \times e^{(4.37 / 2-12) / 7}=0.548,
$$

where the diameter of the fire source $D=\sqrt{4 \mathrm{Q} / \pi q}=$ $\sqrt{(4 \times 7500) /(\pi \times 500)}=4.37 \mathrm{~m}$.

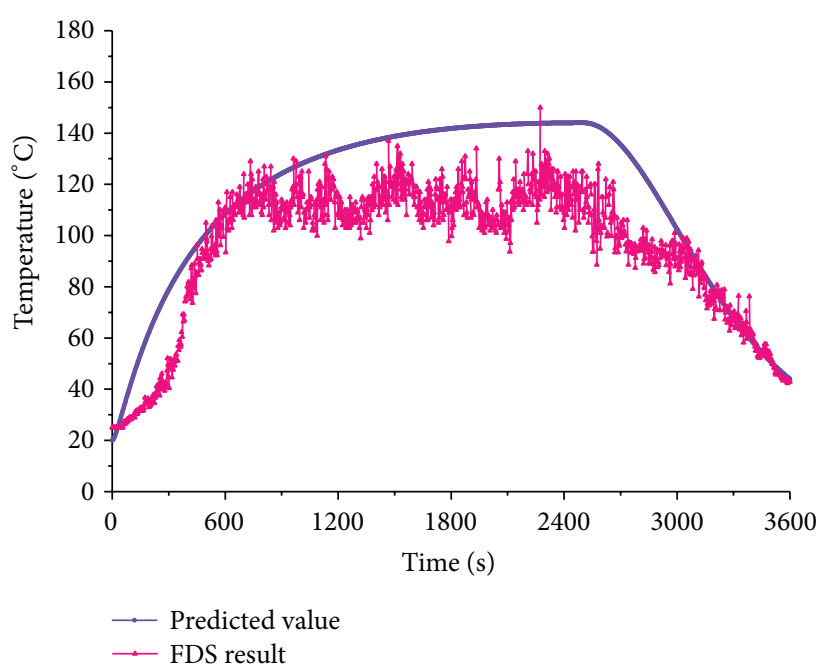

FIGURE 12: The predicted curve based on the new approach is basically consistent with the FDS simulation results.

Therefore, the maximum value of smoke temperature under the ceiling at a distance of $12 \mathrm{~m}$ from the centerline of the fire source during the whole process of the fire is

$$
T_{m}=T_{g}^{\max } \times k_{s m}=227 \times 0.548=124\left({ }^{\circ} \mathrm{C}\right) .
$$

Since the fire power is $7.5 \mathrm{MW}$, the shape coefficient at the growing phase and the steady phase of the fire is recommended as 6 , and the shape coefficient at the decay phase is recommended as 0.08 . The temperature reaches its maximum at $2504 \mathrm{~s}$, and the ambient temperature is $20^{\circ} \mathrm{C}$. Thus, the smoke temperature curve under the ceiling at a distance of $12 \mathrm{~m}$ from the centerline of the fire source can be represented as (26). Figure 12 is a comparison diagram of the temperature prediction curves based on the new approach and the results of FDS large eddy simulation in the case. From Figure 12, we can see that the predicted curve based on the new approach is basically consistent with the FDS simulation result which is far lower than the ISO 834 curve. We have

$$
\begin{gathered}
T_{g}=124 \times e^{-(\ln t-\ln 2504)^{2} / 6}+20, \quad t \leq 2504, \\
T_{g}=124 \times e^{-(\ln t-\ln 2504)^{2} / 0.08}+20, \quad t \geq 2551 .
\end{gathered}
$$

According to (21), we can determine the steel temperature curve as (27), shown in Figure 13. From Figure 13, we can see that the steel temperature still rises in the decay phase and the maximum value of steel temperature appears in this phase. We have

$$
\begin{aligned}
\Delta T=\frac{35 \Delta t}{3768000}[ & 5.67 \times 10^{-8} \times 0.8 \\
& \times\left(\left(T_{g}+273\right)^{4}-\left(T_{s}+273\right)^{4}\right) \\
& \left.+25\left(T_{g}-T_{s}\right)+429\right] .
\end{aligned}
$$




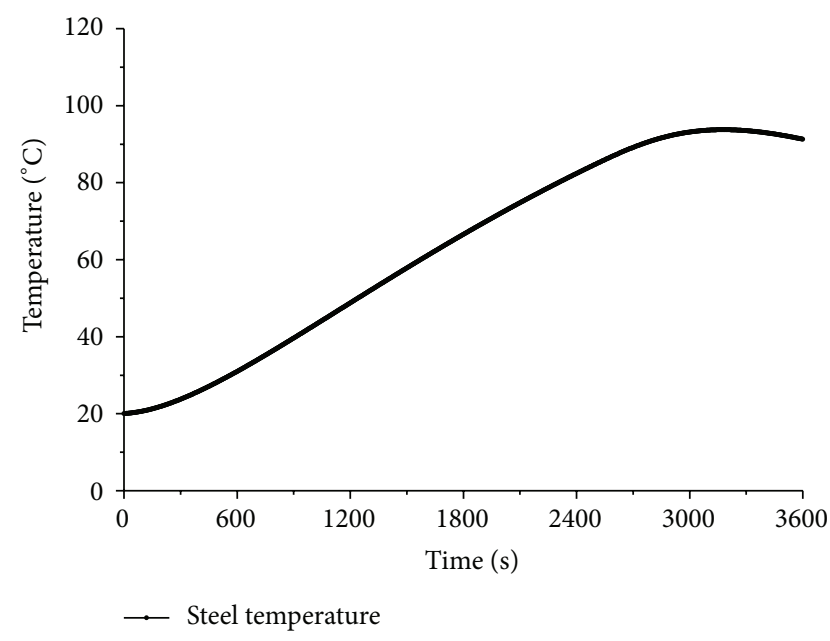

FIGURE 13: Steel temperature predicted by proposed methods in this paper.

\section{Conclusion}

A new approach and a modified model are put forward to accurately predict the smoke and steel temperature development in a large-space fire. These conclusions and experiment data obtained in this paper could provide valuable reference to fire simulation, hazard assessment, and fire protection design. Based on this research, the following conclusions can be drawn.

(1) Based on the full-scale bookcase fire experiment, this paper proposed a fire development model for the whole process of localized fires in large-space buildings. The whole process of a fire includes growing phase, steady phase, and decay phase. Among them, the heat release rate of the fire at the growing phase increases following the rule of the $t^{2}$ fire model; the heat release rate remains constant at the steady phase, whereas it linearly decreases at the decay phase. This model can more accurately and comprehensively reflect the developmental characteristics of localized fires in large-space buildings. In addition, the paper argues that, for localized fires in large-space buildings full of wooden combustibles, fire growing phases can be simplified into a $t^{2}$ fire with the growth coefficient of $0.0346 \mathrm{~kW} / \mathrm{S}^{2}$.

(2) Based on the fire development model for the whole process of localized fires in large-space buildings and assisted by the technology of FDS large eddy simulation, the temperature fields of fire smoke of localized fires in large spaces were investigated with different building heights, building areas, and fire powers. It has been found that for large-space buildings with a height greater than $6 \mathrm{~m}$ and a building area more than $1500 \mathrm{~m}^{2}$, factors like building height and building area can slightly affect the curve trend of smoke temperature, while such factors like fire power have more significant influence on the curve trend of smoke temperature. Through the analysis of temperature curves of fire smoke in various fire scenarios, the paper proposed a whole-process prediction model for the smoke temperature fields of localized fires in large-space buildings. As long as the model uses the appropriate shape coefficient, the prediction model can accurately predict the temperature fields of fire smoke of localized fires in large-space buildings.

(3) The heat transfer between the steel and the flame is ignored in the past steel researches. Now based on the lumped heat capacity method, a modified model of steel temperature development in localized fire is built. In the new model, the localized fire source in large space is treated as one point fire source to evaluate the flame net heat flux to steel which is firstly taken into consideration.

\section{Conflict of Interests}

The authors declare that there is no conflict of interests regarding the publication of this paper.

\section{Acknowledgments}

The research presented in this paper was supported by the Open Foundation of Jiangsu Key Laboratory for Environmental Impact and Structural Safety in Civil Engineering (JSKL2011YB11) and Specialized Research Fund for the Doctoral Program of Higher Education (20120095110027).

\section{References}

[1] O. Pettersson, S. E. Magnusson, and J. Thor, Fire Engineering Design of Steel Structures, Lund Institute of Technology, Lund, Sweden, 1976.

[2] D. J. Latham, B. R. Kirby, and G. Thomson, “The temperatures attained by unprotected structural steelwork in experimental natural fires," Fire Safety Journal, vol. 12, no. 2, pp. 139-152, 1987.

[3] J. I. Ghojel and M. B. Wong, "Heat transfer model for unprotected steel members in a standard compartment fire with participating medium," Journal of Constructional Steel Research, vol. 61, no. 6, pp. 825-833, 2005.

[4] F. Wald, M. Chladná, D. Moore, A. Santiago, and T. Lennon, "Temperature distribution in a full-scale steel framed building subject to a natural fire," Steel and Composite Structures, vol. 6, no. 2, pp. 159-182, 2006.

[5] T. R. Kay, B. R. Kirby, and R. R. Preston, "Calculation of the heating rate of an unprotected steel member in a standard fire resistance test," Fire Safety Journal, vol. 26, no. 4, pp. 327-350, 1996.

[6] L. Gardner and K. T. Ng, “Temperature development in structural stainless steel sections exposed to fire," Fire Safety Journal, vol. 41, no. 3, pp. 185-203, 2006.

[7] T. Z. Harmathy and M. A. Sultan, "Correlation between the severities of the ASTM E119 and ISO 834 fire exposures," Fire Safety Journal, vol. 13, no. 2-3, pp. 163-168, 1988.

[8] ASTM, Standard Methods of Fire Tests of Building Construction and Materials (ASTM Standard E119-05), American Society for Testing and Materials, West Conshohocken, Pa, USA, 2005.

[9] I. F. R. Tests, Elements of Building Construction, ISO-834, International Organization for Standardization, Geneva, Switzerland, 1975.

[10] C. R. Barnett, "Replacing international temperature-time curves with BFD curve," Fire Safety Journal, vol. 42, no. 4, pp. 321-327, 2007. 
[11] A. H. Buchanan, Structural Design for Fire Safety, vol. 273, Wiley, New York, NY, USA, 2001.

[12] C. Gutiérrez-Montes, E. Sanmiguel-Rojas, A. Viedma, and G. Rein, "Experimental data and numerical modelling of 1.3 and 2.3 MW fires in a $20 \mathrm{~m}$ cubic atrium," Building and Environment, vol. 44, no. 9, pp. 1827-1839, 2009.

[13] G. Zhang, G. Zhu, and L. Huang, "Experiment and theoretical model for the temperature development in steel members exposed to fire in the large space building," Journal of China University of Mining and Technolgy, vol. 42, no. 3, pp. 370-374, 2013.

[14] C. L. Shi, M. H. Zhong, T. R. Fu, L. He, and R. Huo, "An investigation on spill plume temperature of large space building fires," Journal of Loss Prevention in the Process Industries, vol. 22, no. 1, pp. 76-85, 2009.

[15] F. Wald, L. Simões da Silva, D. B. Moore et al., "Experimental behaviour of a steel structure under natural fire," Fire Safety Journal, vol. 41, no. 7, pp. 509-522, 2006.

[16] SFPE Handbook of Fire Protection Engineering, National Fire Protection Association, Quincy, Mass, USA, 1988.

[17] National Fire Protection Association, NFPA 204: Standard For Smoke and Heat Venting, National Fire Protection Association, 2002.

[18] K. B. McGrattan and G. P. Forney, Fire Dynamics Simulator: User's Manual, US Department of Commerce, Technology Administration, National Institute of Standards and Technology, 2000.

[19] W. Xue and G.-J. Zhang, "FDS fire simulation and application," Jilin Forestry Science and Technology, vol. 6, pp. 4-8, 2006.

[20] T. G. Ma and J. G. Quintiere, "Numerical simulation of axisymmetric fire plumes: accuracy and limitations," Fire Safety Journal, vol. 38, no. 5, pp. 467-492, 2003.

[21] T.-S. Shen, Y.-H. Huang, and S.-W. Chien, "Using fire dynamic simulation (FDS) to reconstruct an arson fire scene," Building and Environment, vol. 43, no. 6, pp. 1036-1045, 2008.

[22] G. Zhang, G. Zhu, G. Yuan et al., “Temperature model of steel members exposed to thermal radiation and fire in large space building," Journal of Harbin Institute of Technology, vol. 45, no. 6, pp. 96-101, 2013.

[23] Y. Du and G. Li, "A new temperature-time curve for fireresistance analysis of structures," Fire Safety Journal, vol. 54, pp. 113-120, 2012. 


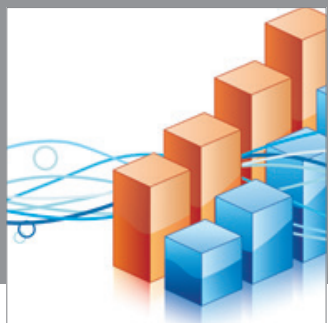

Advances in

Operations Research

mansans

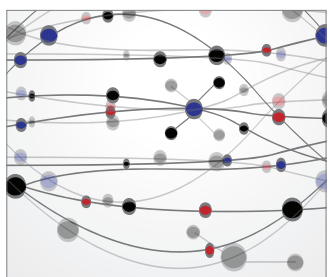

The Scientific World Journal
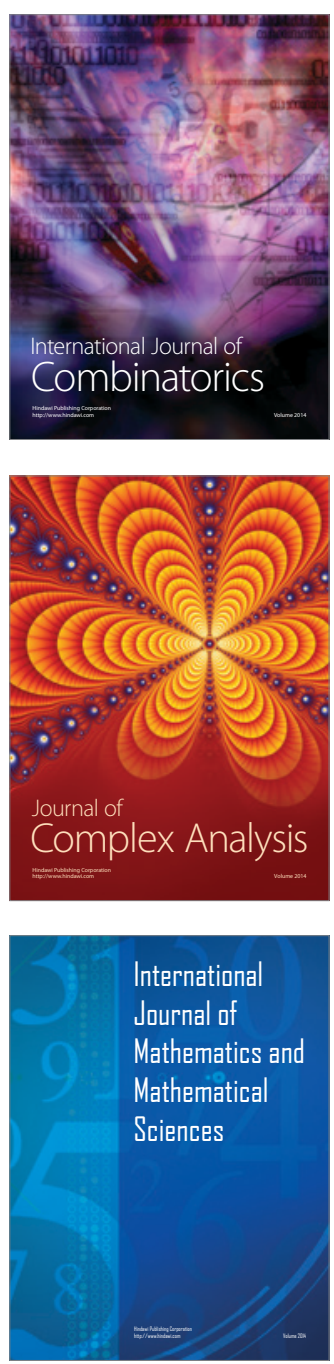
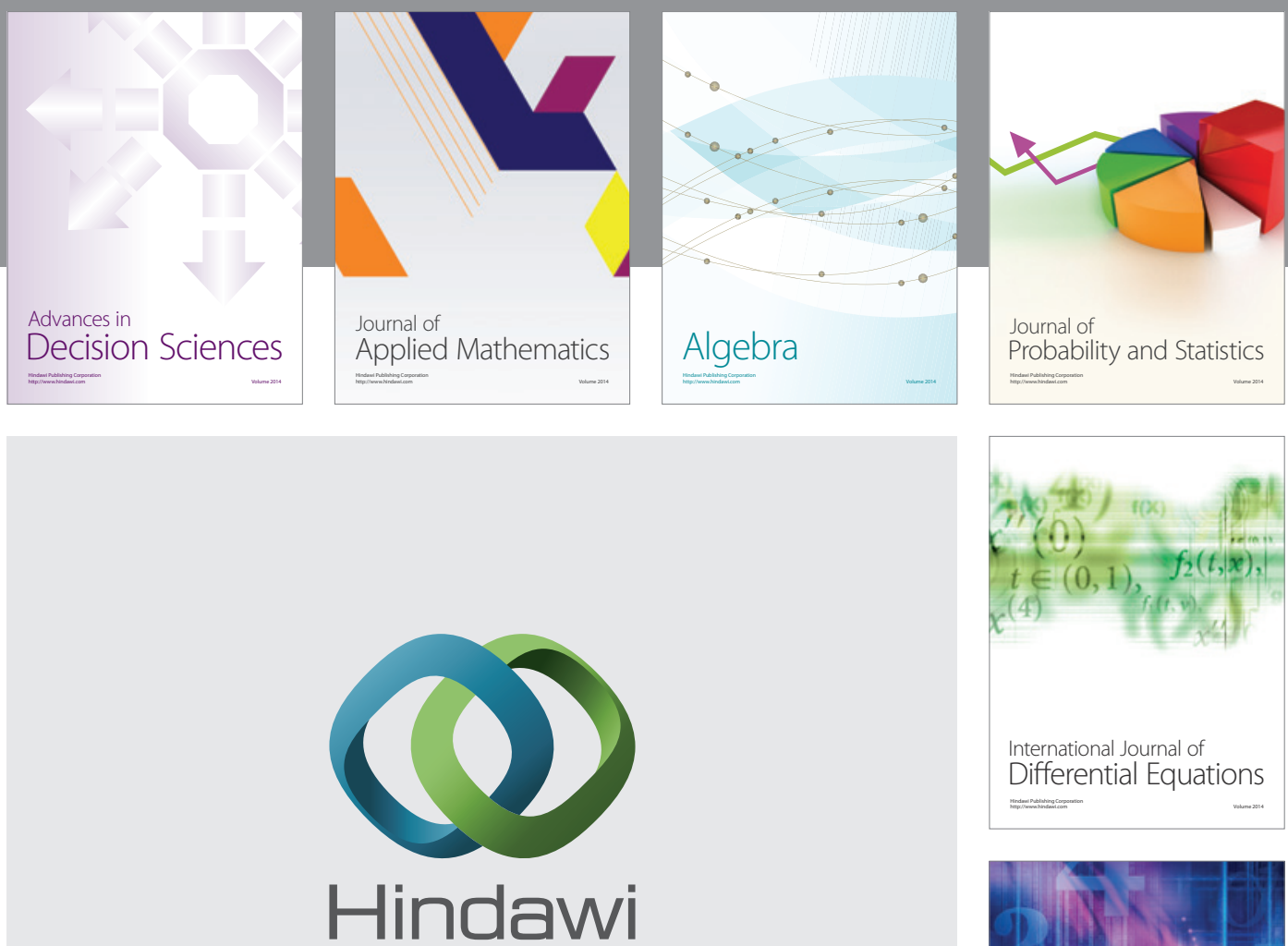

Submit your manuscripts at http://www.hindawi.com
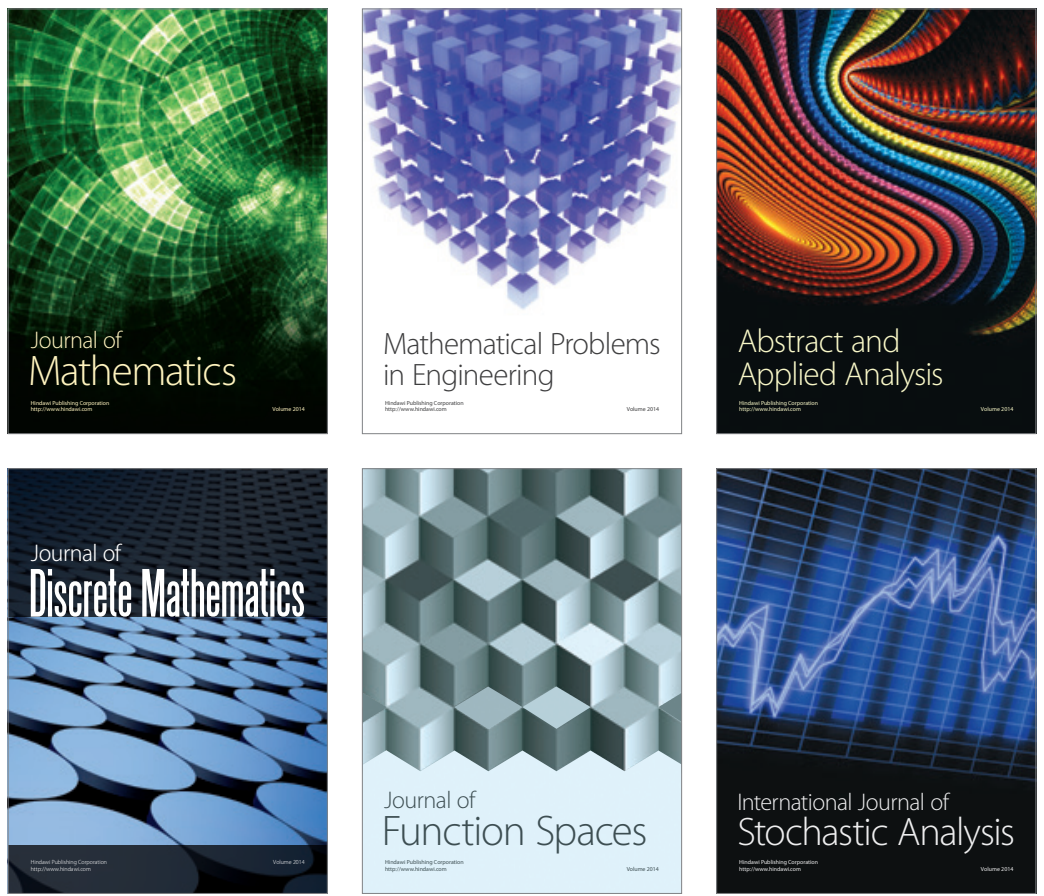

Journal of

Function Spaces

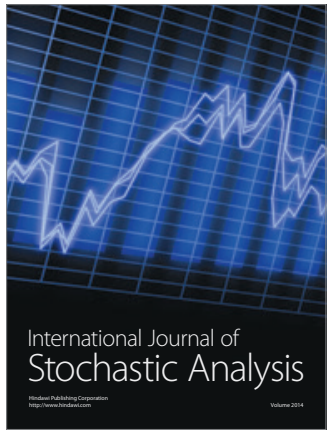

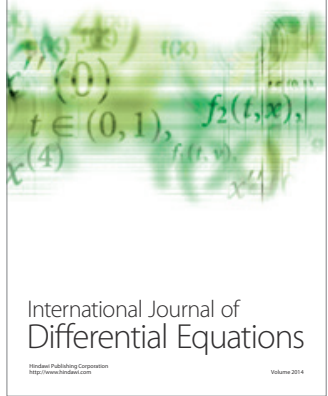
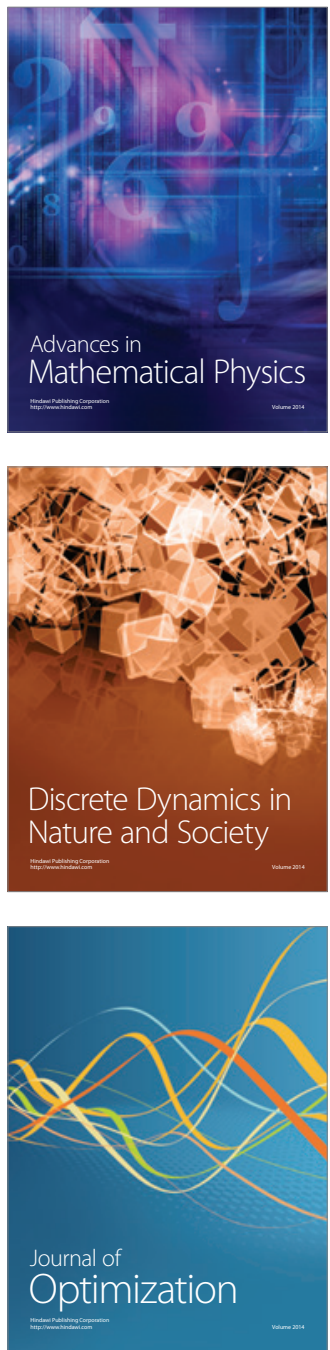